\title{
Epistula imperatoris Hadriani ad Ephesios. List cesarza Hadriana do Efezjan
}

Epistula Imperatoris Hadriani ad Ephesios. Emperor Hadrian's Letter to the Ephesians Epistula imperatoris Hadriani ad Ephesios. Письмо императора Адриана к ефесянам

\author{
KONRAD TADAJCZYK \\ Dr, Uniwersysytet Łódzki \\ e-mail: tktadajczyk@wpia.uni.lodz.pl, https://orcid.org/0000-0002-2487-8163
}

\begin{abstract}
Streszczenie: Cesarz Hadrian poświęcał dużo uwagi funkcjonowaniu rad miejskich miast greckich. Przedstawiony artykuł zawiera oryginalne teksty cesarskich listów związane z wyborem członków rady miejskiej Efezu. Listy zostały przetłumaczone oraz wyposażone w aparat krytyczny.
\end{abstract}

Słowa kluczowe: Hadrian, Efez rada miejska, wybory, żeglarz

Summary: Emperor Hadrian devoted much of his attention to the problems of the functioning of the councils of Greek towns. This work contains the original texts of the emperor's letters connected with the problem of selecting town councilors of Ephesus. The texts were translated and equipped with critical comments.

Key words: Hadrian, Ephesus' town council, election, sailors

Резюме: Император Адриан уделял большое внимание функционированию городских советов греческих городов. Представленная статья содержит оригинальные тексты императорских писем, связанных с выборами членов городского совета Эфеса. Письма переведены и снабжены критическим аппаратом.

Ключевые слова: Адриан, городской совет Эфеса, выборы, мореплаватель

\section{Wstęp}

Rzymianie byli ludźmi ruchliwymi i dużo podróżowali czy to w interesach, służbowo, czy dla zdrowia i wreszcie w celach turystycznych ${ }^{1}$. Chociaż mieszkali na półwyspie otoczonym wodami, początkowo nie dostrzegali dobrodziejstwa morza jako szlaku wodnego, widząc w nim tylko groźny i niszczycielski żywioł. Nie zaliczali się do dobrych żeglarzy i podróżowali w państwie przeważnie droga lądową ${ }^{2}$. Drogę morską zaczęli wykorzystywać szerzej po podbiciu basenu Morza Śród-

1 J. Wielowiejski, Na drogach i szlakach Rzymian, Warszawa 1984, s. 211.

2 L. Casson, Podróże w starożytnym świecie, wstęp i red. T. Kotula, tłum. A. Flasińska, M. Radlińska-Kardaś, Wrocław 1981, s. 105-106. 
ziemnego i zwalczeniu plagi piractwa przez Pompejusza Wielkiego (67 r. p.n.e.) ${ }^{3}$. W cesarstwie zaczęli szerzej doceniać szlaki morskie, pomimo grożących na nich niebezpieczeństw. Szybkość tego rodzaju transportu, np. przewóz zboża z Egiptu do Italii, uznana została za wystarczające uzasadnienie podejmowania ryzykownych przepraw morskich. Pliniusz Starszy w swojej Historii naturalnej opisując len, którego używano do wyrobu żagli, podał, że podróż morska z Aleksandrii do Rzymu trwała bardzo krótko - od sześciu do dziewięciu dni. Dawniejsi badacze uważali, że w starożytności pływano tylko latem, według najnowszych badań sezon żeglugowy trwał cały rok, a Rzymianie korzystali bardzo często z tego wygodnego środka transportu ${ }^{4}$. Urzędnicy rzymscy, by dotrzeć na prowincje, gdzie mieli objąć swoje stanowiska, również korzystali z drogi wodnej. $j^{5}$ Oktawian August lubił podróże morskie, podobnie jak nieco później cesarz Hadrian, który podróżował w trakcie całego swojego panowania i korzystał kilkukrotnie z dróg morskich. Tak jak Wespazjan, który 50 lat wcześniej popłynął z Aleksandrii na Rodos statkiem handlowym ${ }^{6}$, tak Hadrian wykorzystał prywatne statki handlowe dla transportu swojej świty, zamiast korzystać z floty cesarskiej classis praetoria, która stacjonowała w Misenium i Rawennie ${ }^{7}$. Korzystanie z prywatnych usług żeglarzy miało na

3 A. Tarwacka, Status piratów w świetle rzymskiego prawa publicznego $i$,ius gentium”, Zeszyty Prawnicze 2005, t. 5, nr 2, s. 90.

4 S. Ducin, Sztuka nawigacji w starożytnej Grecji i w Rzymie, Lublin 1997, s. 59-92. Zob. też szerzej J. Jundziłł, Rzymianie i morze, Bydgoszcz 1991.

5 „Plin., Ep X 15, 17A: Quia confido, domine, ad curamtuam pertinere, nuntio tibi me Ephesam cum

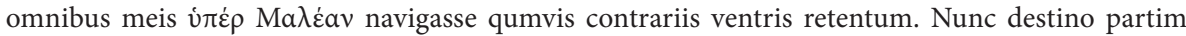
orariis navibus, partim vehiculis provinciam petere. Nam sicut itineri graves aestus ita continuae navigationi etesiae reluctantur. Przypuszczam, że się tym martwisz, Panie, dlatego donoszę, iż żeglując ponad przylądkiem Maleas dotarliśmy wszyscy, mimo niesprzyjających wiatrów, do Efezu. Drogę do prowincji zamierzam przebyć częściowo lekkim statkiem, częściowo wozem, bo podróżując wyłącznie lądem trzeba się zmagać z upałem, a wybierając drogę morską - z etezjami”. Korespondencja Pliniusza Młodszego z cesarzem Trajanem, tekst i tłum. A. Dębiński, M. Jońca, I. Learczyk, A. Łuka, Lublin 2017, s. 215; „17A Sicut sauberrimam navigatine, domine, usque ad Ephesum expertus ita inde, postquam vehiculis iter facere coepi, gravissimis aestibus atque etiam febriculis vexatus Pergami substiti. Rursus, cum transsissem in orarias naviculas, contrariis ventris retentus aliquanto tardius, quam speraveram, is ist XV kal. Octobres, Bithyniam intravi. O ile mija podróż morska do Efezu była pomyślna, Panie, o tyle droga lądowa z Efezu nieznośna z powodu upałów, na dodatek zdarzało mi się gorączkować, więc zatrzymałem się w Pergamonie. Gdy się znowu przesiadłem na statek, z powodu niepomyślnych wiatrów dotarłem do Bitynii 17 września, czyli nieco później, niż planowałem.., Korespondencja Pliniusza Młodszego z cesarzem Trajanem..., s. 219.

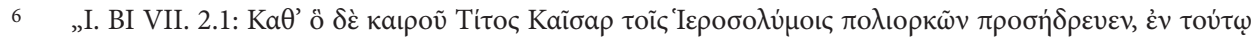

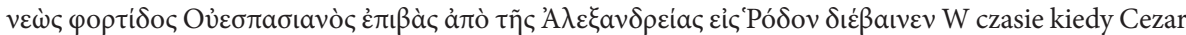
Tytus wytrwale oblegał Jerozolimę, Wespazjan wsiadł na okręt handlowy i popłynął z Aleksandrii na Rodos". Józef Flawiusz, Wojna żydowska, wstęp, tłum., komentarz J. Radożycki, Warszawa 1992, s. 399.

7 H. Halfmann, Itineria principium. Geschischte und Typologie der Kaiserreisen im Römischen Reich, Stuttgart 1986, s. 72. 
celu zmniejszenie kosztów przewozu towarzyszy cesarza i zaopatrzenia. Podczas jednej z jego licznych podróży morskich napisał listy polecające do rady miejskiej Efezu dla dwóch kapitanów Lucjusza Erasta i Filokyriosa, z usług których korzystał. Hadrian musiał o nich słyszeć, znać i cenić, skoro zaangażował obu żeglarzy do podróży. Sam cesarz podróżował na własnym okręcie cesarskim, oni przewozili członków jego świty i zaopatrzenie ${ }^{8}$.

Listy brzmią identyczne, zmienia się tylko nazwisko kandydata, o którego cesarz prosi. Zostały one umieszczone na ścianie budowli, zidentyfikowanej jako

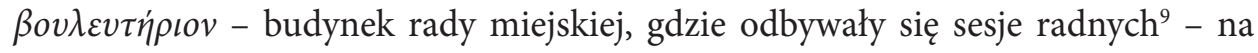
honorowym miejscu ${ }^{10}$, co wskazuje na to, że dla mieszkańców Efezu były ważne.

\section{Tekst grecki}

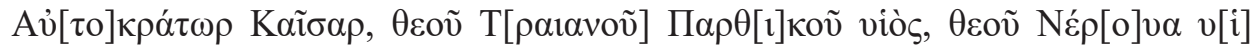

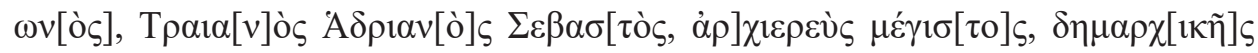

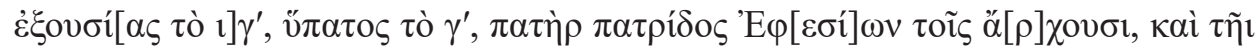

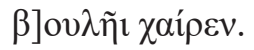

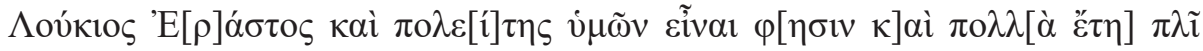

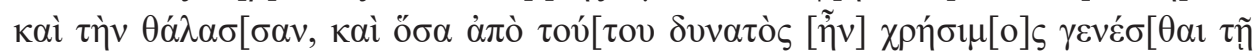

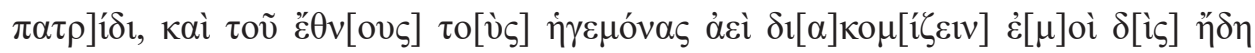

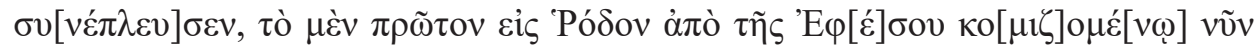

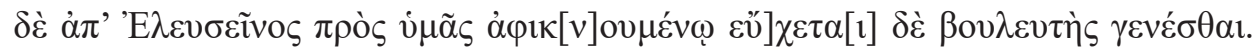

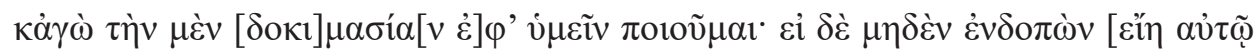

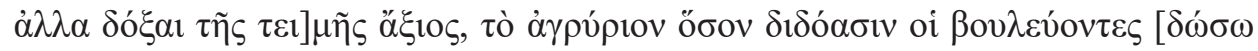

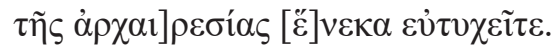

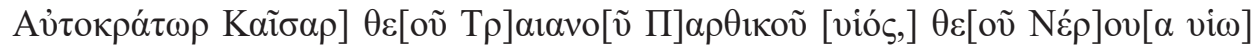

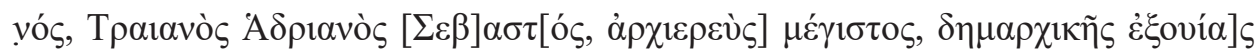

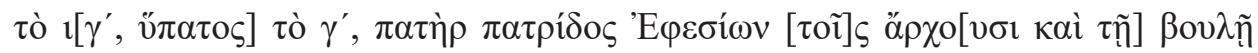

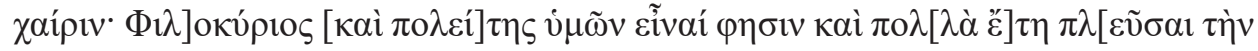

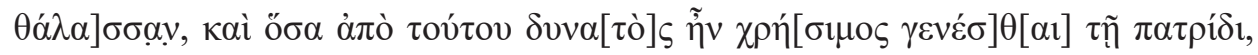

8 A.R. Birley, Hadrian cesarz niestrudzony, tłum. R. Wiśniewski, Warszawa 2002, s. 261.

9 S. Cramme, Die Bedeutung des Euergetismus für die Finanzierung städtischer Aufgaben in der Provinz Asia, Köln 2001, s. 194.

10 E.L. Bowie, Hadrien et Éphèse, red. A. Hostein, Les voyages des empereurs dans l'Orient romain. Époque antonine et sévérienne, Arles 2012, s. 268. 


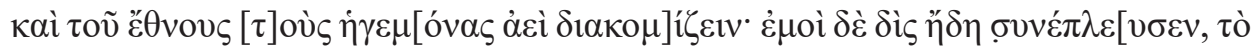

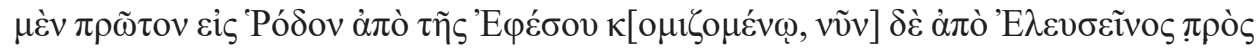

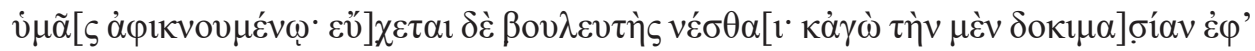

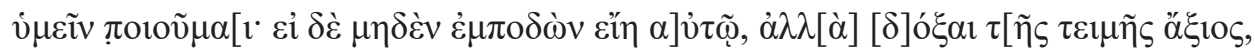

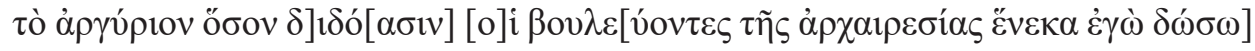
$[\varepsilon \dot{\tau} \tau \chi \chi \varepsilon \tilde{\tau} \tau \varepsilon]^{11}$.

\section{Tekst polski}

Imperator Cezar, syn boskiego Trajana Partyjskiego, wnuk boskiego Nerwy, Trajan Hadrian August, kapłan najwyższy, mający władzę trybuńską po raz trzynasty, konsul po raz trzeci, ojciec ojczyzny pozdrawia urzędników, członków rady miejskiej, Efezu. Lucjusz Erast, wasz obywatel, mówi, że przez wiele lat pływał na morzu i był użyteczny dla ojczyzny, zawsze przewozi namiestników prowincji. Ze mną płynął już dwa razy, pierwszy raz z Efezu na Rodos, teraz, gdy przybywam do was z Eleusis. Pragnie zostać członkiem rady. Zostawiam weryfikacje wam: jeżeli nic nie będzie stało na przeszkodzie i wyda się godny zaszczytu, zapłacę całą sumę, którą radni płacą w związku z wyborami. Miejcie powodzenie.

Imperator Cezar, syn boskiego Trajana Partyjskiego, wnuk boskiego Nerwy, Trajan Hadrian August, kapłan najwyższy, mający władzę trybuńską po raz trzynasty, konsul po raz trzeci, ojciec ojczyzny, pozdrawia urzędników, członków rady miejskiej Efezu. Filokyrios wasz obywatel mówi, że przez wiele lat pływał na morzu i był użyteczny dla ojczyzny, zawsze przewozi namiestników prowincji. Ze mną płynął już dwa razy, pierwszy raz z Efezu na Rodos, teraz, gdy przybywam do was z Eleusis. Pragnie zostać członkiem rady. Zostawiam weryfikacje wam: jeżeli nic nie będzie stało na przeszkodzie i wyda się godny zaszczytu, zapłacę całą sumę, którą radni płacą w związku z wyborami. Miejcie powodzenie.

11 Tekst grecki listów za: L. Bier, The Bouleuterion at Ephesos, Wien 2011, s. 91-92. Tłumaczenie autora. 


\section{Komentarz}

Hadrian przedstawiając kapitanów statków, zwraca uwagę na ich doświadczenie. Pływają oni na morzu wiele lat i wyświadczali przysługi państwu rzymskiemu. Rzymianie wykorzystywali flotę statków kupieckich do transportu urzędników państwa od czasów republiki ${ }^{12}$. Wielokrotnie przewozili namiestników do prowincji azjatyckich. Cesarz wspomina, że także on sam korzystał dwukrotnie z usług tych żeglarzy. Po raz pierwszy, na przełomie września i października 124 po Chr. Hadrian wracał wtedy z ważnej podróży na Wschód, gdzie udało mu się zażegnać kolejną wojnę z państwem partyjskim ${ }^{13}$. Prynceps wracał niespiesznie, odwiedzając miasta greckie w Azji, kierując się do Efezu. W tym mieście spędził dwa miesiące, a także został uhonorowany hymnem odśpiewanym przez efebów ${ }^{14}$.

Opuszczając miasto, przed powrotem do Grecji Hadrian udał się drogą morską na Rodos, by w październiku znaleźć się w Eleusis. Drugą podróż cesarz odbył pięć lat później, w marcu 129 po Chr., płynął wtedy po raz drugi z Grecji do Efezu, udając się przez Azję do Syrii. Podczas tej podróży napisał listy polecające dla obu kapitanów przewożących jego i jego towarzyszy.

Hadrian po przedstawieniu kapitanów zwraca się z prośbą do archontów i rady Efezu o przyjęcie Erastosa i Filokyriosa jako radnych miasta. Cesarz nie prosi o zrzeczenie się prerogatyw urzędników przy wyborze radnych, ale gotów jest zapłacić wpisowe, jeśli spełnią określone warunki. List Hadriana pokazuje sposób wyłaniania członków rad w miastach greckich tego okresu. Kandydaci musieli poddać

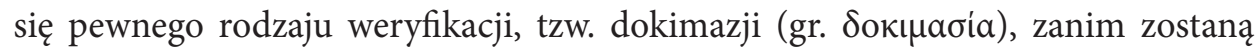

12 W.V. Harris, Roman Governments and Commerce, 300 B.C.-A.D. 300, w: Mercanti e politica nel mondo antico, red. C. Zaccagnini, Roma 2003, s. 291.

13 „SHA, Hadr. 12,8: Bellum Parthorum per idem tempus in motu tantum fuit, idque Hadriani conloquio repressum est. Wojna z Partami, ledwie wówczas zaczęta, wstrzymana została na skutek rozmowy z Hadrianem". Historycy cesarstwa rzymskiego, tłum. H. Szelest, Warszawa 1966, s. 36.

14 Tekst grecki za E.M. Smallwood, Documents illustrating the principates of Nerva, Trajan and Hadrian,

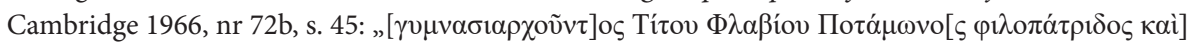


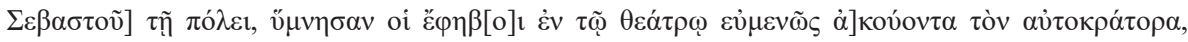

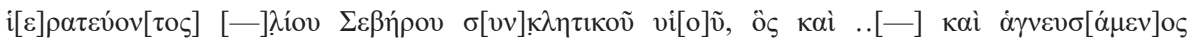

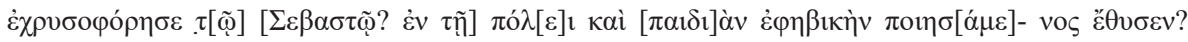

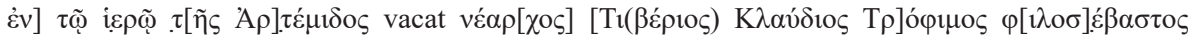

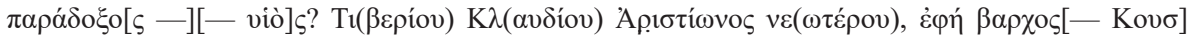

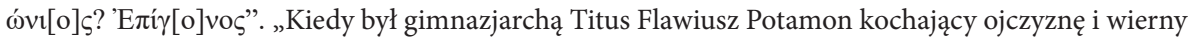
Augustowi i w mieście przebywał władca Imperator Trajan Hadrian Cezar August efebowie zaśpiewali hymn $\mathrm{w}$ teatrze przed słuchającym z przyjemnością imperatorem, kapłanem [...] synem senatora Sewera, który złożył ofiarę zasięgającemu wróżby Augustowi w mieście złożył ofiarę w świątyni Artemidy uczynił chłopców efebami.... Tłumaczenie autora. 
powołani na urząd. Nie jest jednak jasne, czy wszędzie dotyczyła ona odpowiedniego wieku, wysokości majątku kandydata czy też wymagała od nich posiadania określonego statusu społecznego ${ }^{15}$. Wybór do rady miejskiej wiązał się z uznaniem, jakim zostali obdarzeni przez współobywateli za działanie na rzecz wspólnoty miejskiej ${ }^{16}$. Członkowie rady miejskiej cieszyli się także przywilejami, np. specjalnym traktowaniem członków w świetle prawa karnego jako honestiores ${ }^{17}$. Nic nie wiadomo o pochodzeniu społecznym obu kapitanów. Nie posiadali obywatelstwa rzymskiego ${ }^{18}$. Ich imiona (Erastos i Filokyrios) były często stosowane w świecie greckim. Czy byli jednak wyzwoleńcami jakiś bogatych mieszkańców Efezu - jak sugerują Th. Drew-Bear, F. Richard - nie do końca da się rozstrzygnąćc ${ }^{19}$. Obaj kapitanowie mieli własne statki, nie mogli należeć zatem do niższych warstw społeczeństwa. Byli pomocni administracji rzymskiej, przewożąc jej urzędników. Hadrian obu marynarzy znał i cenił, skoro zaangażował obu żeglarzy do podróży.

Nowo wybrani członkowie rady musieli uiścić do kasy miejskiej odpowiednią opłatę. Mówi o tym ustawa pompejańska z I w. przed Chr. nadana przez Gnejusza Pompejusza Wielkiego, która regulowała prawne funkcjonowanie administracji miast w państwie. Jej treść nie zachowała się do naszych czasów, a wiadomości o niej pochodzą jedynie z listów Pliniusza Młodszego do Trajana (list $79^{20}$ oraz list 112), w którym Pliniusz przekazuje, że wybierani nadliczbowi radni miast powinni wpłacać wpisowe do kasy miejskiej. Sama ustawa pompejańska nie wprowadzała tego typu opłat, nałożono je dopiero w okresie cesarstwa ${ }^{21}$. Dion Chryzostom,

15 S. Dmitriew, City Government in Hellenistic and Roman Asia Minor, Oxford 2005, s. 157.

16 Korespondencja Pliniusza Młodszego z cesarzem Trajanem..., s. 125.

17 K. Amielańczyk, Rzymskie prawo karne w reskryptach cesarza Hadriana, Lublin 2006, s. 234-238; K.M. Coleman, Fatal Charades: Roman Executions Staged as Mythological Enactments, The Journal of Roman Studies 2000, t. 80, s. 55.

18 M.T. Boatwright, Hadrian and the Cities of the Roman Empire, Princeton 2002, s. 81.

19 Th. Drew-Bear, F. Richard, Hadrien et Erastos, nauclère d'Éphèse, w: L'Afrique, la Gaule, la religion à l’époque romaine. Mélanges à la mémoire de Marcel Le Glay, red. Y. de Bohec, Bruxelles 1994, s. 747.

20 „Plin., Ep X: Cautum est, domine, Pompeia lege, quae Bithinis data est, ne quis capiat magistratum neve sit in senatu minor annorum triginta. Panie, ustawa pompejańska uchwalona dla Bityńczyków, stanowi, aby nie obejmował urzędu ani nie zasiadał w senacie nikt poniżej trzydziestego roku życia”. Korespondencja Pliniusza Młodszego z cesarzem Trajanem..., s. 352-353.

21 „Plin., Ep X 112: Lex Pompeia, domine, qua Bithyni et Pontici utuntur, eos, qui in bulen a censoribus leguntur, dare pecuniam non iubet; sed ii, quos indulgentia tua quibusdam civitatibus super legitimum numerum adicere permisit, et singula milia denariorum et bina intulerunt. Anicius deinde Maximus proconsul eos etiam, qui a censoribus legerentur, dumtaxat in paucissimis civitatibus aliud aliis iussit inferre. Superest ergo, ut ipse dispicias, an in omnibus civitatibus certum aliquid omnes, qui deinde buleutae legentur, debeant pro introitu dare. Nam, quod in perpetuum mansurum est, a te constitui decet, cuius factis dictisque debetur aeternitas. Panie! Ustawa pompejańska, która stosują mieszkańcy Bitynii i Pontu, zwalnia z wpisowego wszystkich, którzy zostali wpisani przez cenzorów 
który posłował do Trajana i uzyskał zgodę cesarza na powiększenie rady miasta Pruzy o stu członków, chwalił się później, że uczynił swoją ojczyznę bardziej szanowaną i bogatszą przez uzyskanie dodatkowych funduszy miasta ${ }^{22}$. Listy Pliniusza przekazują wiadomości o funkcjonowaniu i wyborze urzędników w czasach dynastii Antoninów.

\section{Bibliografia}

Amielańczyk K., Rzymskie prawo karne w reskryptach cesarza Hadriana, Lublin 2006.

Bier L., The Bouleuterion at Ephesos, Wien 2011.

Birley R.A., Hadrian cesarz niestrudzony, tłum. R. Wiśniewski, Warszawa 2002.

Boatwright T.M., Hadrian and the Cities of the Roman Empire, Princeton 2000.

Bowie L.E., Hadrien et Éphèse, red. A. Hostein, Les voyages des empereurs dans l'Orient romain. Époques antonine et sévérienne, Arles 2012.

Coleman M.K., Fatal Charades: Roman Executions Staged as Mythological Enactments, The Journal of Roman Studies 2000, t. 80.

Cramme S., Die Bedeutung des Euergetismus für die Finanzierung städtischer Aufgaben in der Provinz Asia, Köln 2001.

Dmitriew S., City Government in Hellenistic and Roman Asia Minor, Oxford 2005.

Drew-Bear Th., Richard F., Hadrien et Erastos, nauclère d'Éphèse, w: L'Afrique, la Gaule, la religion à lépoque romaine. Mélanges à la mémoire de Marcel Le Glay, red. Y. de Bohec, Brueglem 1994.

na listę członków rady miejskiej, ale w niektórych miastach, ci, których w swojej łaskawości pozwoliłeś wybierać ponad liczbę przewidzianą w ustawie, wpłacali po tysiąc albo dwa tysiące denarów. Następnie prokonsul Anicjusz Maksymus wprowadził w kilku miastach taryfę opłat obejmującą nawet tych z liczby ustawowej. Pozostaje Ci więc rozstrzygnąć, czy we wszystkich miastach nowo wybrani rajcy mają płacić wpisowe, bo ustanawiać to, co ma trwać wiecznie, wypada jedynie Tobie, którego czynom i słowom należy się nieśmiertelność". Korespondencja Pliniusza Młodszego z cesarzem Trajanem..., s. 423, zob. F. Millar, The Greek City in the Roman Period, w: The Ancient Greek City-State: Symposium on the Occasion of the 250th Anniversary of the Royal Danish Academy of Sciences and Letters, July 1-4, 1992, red. Mogens H. Hansen, Copenhagen 1993, s. 232-260.

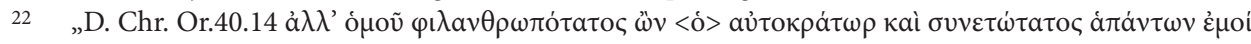

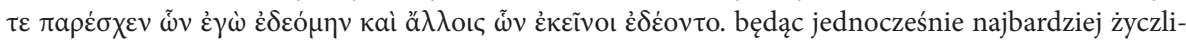
wym i najmądrzejszym ze wszystkich ludzi, cesarz nie tylko dał mi to, o co prosiłem ale także dał in-

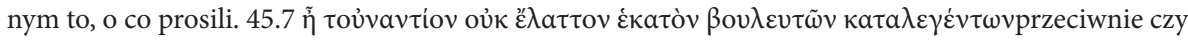
wciągnięto na listę nie mniej niż stu radnych,... 48.1 ö

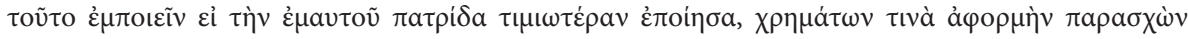
$\ddot{\omega} \sigma \pi \varepsilon \rho$ ảं wam W takim razie czy uważacie że ja to uczyniłem jeśli moja ojczyzna jest bardziej czczona, i podobnie jak pewien kapitał pieniężny dostarczony $\mathrm{z}$ wpisowego za uczestnictwo w radzie i na Zeusa przez zwiększenie dochodów dla finansów miejskich”. Tłumaczenie autora. 
Ducin S., Sztuka nawigacji w starożytnej Grecji i w Rzymie, Lublin 1997.

Halfmann H., Itineria principum. Geschichte und Typologie der Kaiserreisen im Römischen Reich, Stuttgart 1986.

Harris V.W., Roman Governments and Commerce, 300 B.C.-A.D. 300, w: Mercanti e politica nel mondo antico, red. C. Zaccagnini, Roma 2003.

Jundziłł J., Rzymianie i morze, Bydgoszcz 1991.

Korespondencja Pliniusza Młodszego z cesarzem Trajanem, tekst i tłum. A. Dębiński, M. Jońca, I. Leraczyk, A. Łuka, Lublin 2017.

Millar F., The Greek City in the Roman Period, w: The Ancient Greek City-State: Symposium on the Occasion of the 250th Anniversary of the Royal Danish Academy of Sciences and Letters, July 1-4, 1992, red. Mogens H. Hansen, Copenhagen 1993.

Smallwood M.E., Documents illustrating the principates of Nerva, Trajan and Hadrian, Cambridge 1966.

Tarwacka A., Status piratów w świetle rzymskiego prawa publicznego i „ius gentium”, Zeszyty Prawnicze 2005, t. 5, nr 2.

Wielowiejski J., Na drogach i szlakach Rzymian, Warszawa 1984. 